Delft University of Technology

\title{
The performance of CryoSat-2 fully-focussed SAR for inland water-level estimation
}

Kleinherenbrink, Marcel; Naeije, Marc; Slobbe, Cornelis; Egido, Alejandro; Smith, Walter

DOI

10.1016/j.rse.2019.111589

Publication date

2020

Document Version

Accepted author manuscript

Published in

Remote Sensing of Environment

\section{Citation (APA)}

Kleinherenbrink, M., Naeije, M., Slobbe, C., Egido, A., \& Smith, W. (2020). The performance of CryoSat-2 fully-focussed SAR for inland water-level estimation. Remote Sensing of Environment, 237, [111589]. https://doi.org/10.1016/j.rse.2019.111589

\section{Important note}

To cite this publication, please use the final published version (if applicable).

Please check the document version above.

\section{Copyright}

Other than for strictly personal use, it is not permitted to download, forward or distribute the text or part of it, without the consent of the author(s) and/or copyright holder(s), unless the work is under an open content license such as Creative Commons.

\section{Takedown policy}

Please contact us and provide details if you believe this document breaches copyrights.

We will remove access to the work immediately and investigate your claim. 


\title{
The performance of CryoSat-2 fully-focussed SAR for inland water-level estimation
}

\author{
Marcel Kleinherenbrink ${ }^{\mathrm{a}, *}$, Marc Naeije ${ }^{\mathrm{a}}$, Cornelis Slobbe ${ }^{\mathrm{b}}$, Alejandro \\ Egido $^{\mathrm{c}, \mathrm{d}}$, Walter Smith ${ }^{\mathrm{c}}$ \\ ${ }^{a}$ Astrodynamics and Space Missions, Delft University of Technology \\ ${ }^{b}$ Geoscience and Remote Sensing, Delft University of Technology \\ ${ }^{c}$ NOAA Laboratory for Satellite Altimetry \\ ${ }^{d}$ Global Science \& Technology, Inc.
}

\begin{abstract}
This paper applies the Fully-Focussed SAR (FF-SAR) algorithm to CryoSat-2 full-bit-rate data to measure water levels of lakes and canals in the Netherlands, and validates these measurements by comparing them to heights measured by gauges. Over Lake IJssel, a medium-sized lake, the FF-SAR height is biased about $6 \mathrm{~cm}$ below the gauge height, and a similar bias is found at six sites where CryoSat- 2 crosses rivers and canals. The precision of the FF-SAR measurements depends on the extent of multi-looking (incoherent averaging along-track) applied. Over Lake IJssel the precision varies from 4 to $11 \mathrm{~cm}$, decreasing as multi-looking increases. The precision of FF-SAR with $100 \mathrm{~m}$ of multi-looking is equivalent to that of the standard delay/Doppler processing, which has an along-track resolution of about $300 \mathrm{~m}$. The width and orientation of rivers and canals limits the maximum available multi-looking. After removing the $6 \mathrm{~cm}$ bias, FF-SAR heights of rivers and canals have an accuracy between $2 \mathrm{~cm}$ and several decimeters, primarily depending on the presence of other water bodies lying within the cross-track measurement footprint, as these contaminate the waveform. We demonstrate that FF-SAR processing is able to resolve and measure small ditches only a few meters in width. The visibility of these signals depends on the angle at which CryoSat-2 crosses the ditch and on whether or
\end{abstract}

\footnotetext{
${ }^{*}$ Corresponding author

Email address: m.kleinherenbrink@tudelft.nl (Marcel Kleinherenbrink)
} 
not the ditch remains straight within CryoSat-2's field of view. In the bestcase scenario, straight ditches at nearly $90^{\circ}$ to the CryoSat-2 ground track, the ditch signal has high enough signal-to-noise to allow sub-decimeter accuracy of FF-SAR height measurement.

Keywords: CryoSat-2, FF-SAR, Altimetry, Inland water, Validation

\section{Introduction}

The successful launch of CryoSat-2 in April 2010 began a new era in satellite radar altimetry. CryoSat-2, and its successors Sentinel-3\&B and Sentinel-6, have a Synthetic Aperture Radar (SAR) mode [28] that enables bursts of pulses to be 5 processed coherently to narrow the along-track dimension of the measurement footprint via Doppler beam sharpening. The SAR mode was designed to support delay/Doppler altimetry [19, which applies coherent processing only within each burst and achieves an along-track resolution of about $300 \mathrm{~m}$. Egido $\&$ Smith [10] showed that SAR pulse echoes can be coherently processed across a sequence of bursts, a method they called Fully Focused SAR (FF-SAR) altimetry. FF-SAR can narrow the along-track resolution to $0.5 \mathrm{~m}$ and can be applied to Sentinel3A\&B and Sentinel-6 as well as CryoSat-2 10, 13. With FF-SAR it should be possible to detect water bodies much smaller than can be "seen" by conventional [4, 1, 6, 11, 7, 21] or delay/Doppler [18, 25, 26, 27, 12, 2, 20] altimetry, and to measure not only the water surface height but also the along-track extent of the water covered area. Where this extent is large, "multi-looking" [10, 28, can also improve the height precision beyond that of delay/Doppler altimetry [10].

This paper presents new and significant aspects of FF-SAR altimetry of inland waters not previously known. We apply FF-SAR to CryoSat-2 data over lakes, rivers, canals and ditches in the north of the Netherlands, where water levels are controlled, gauged to the national Amsterdam Ordnance Datum (NAP), and convertible to ellipsoidal heights via the NLGEO2018 quasi-geoid [22]. The larger lakes are monitored by multiple gauges and most gauges sample height every 10 minutes, so water levels can be corrected for the effects 
of wind, and the errors in interpolating water height to the time and place of FF-SAR measurement are very small, which is especially important for satellite altimeters with long-repeat orbits, as they pass over different parts of the lake. This allows us to validate CryoSat-2's FF-SAR height measurements in terms of its absolute accuracy (that is, "bias") as well as its precision. Over a

so large lake, Lake IJssel, we determine the bias and precision of FF-SAR water height as a function of the along-track extent of multi-looking, demonstrating the advantage of FF-SAR's increased number of independent looks with respect to delay/Doppler. We compare the bias and precision of FF-SAR water heights over small rivers, canals and ditches to the Lake IJssel results to examine how the accuracy of measurement depends on the geometry and orientation of the water body. Finally, we show that FF-SAR can distinguish a canal from a ditch and measure the heights of both accurately to about a decimeter when the two are separated by only a few meters and the ditch is only a few meters wide. This capability may allow altimeters to study and monitor water resources with unprecedented spatial resolution.

\section{Study area}

We limit the validation to gauged water bodies in the North of the Netherlands, where CryoSat-2 operates in the SAR mode. A map of the study area is given in figure 1. The lake considered in this study is Lake IJssel, which enclosed by two dams: the Afsluitdijk in the North and the Houtribdijk in the South. Its surface area is approximately $1100 \mathrm{~km}^{2}$. The water level is monitored by multiple gauges distributed over the lake. A list of the gauges used in this study is presented in table 1. The lake is free of tides and on average the water-level variations are on the order of a decimeter. However, differences of more than a meter can occur between opposite sides of the lake in case of strong winds. Over the considered eight-year period (2010-2018), CryoSat-2 crosses Lake IJssel 135 times.

The six canal and river segments considered in this study are located around 


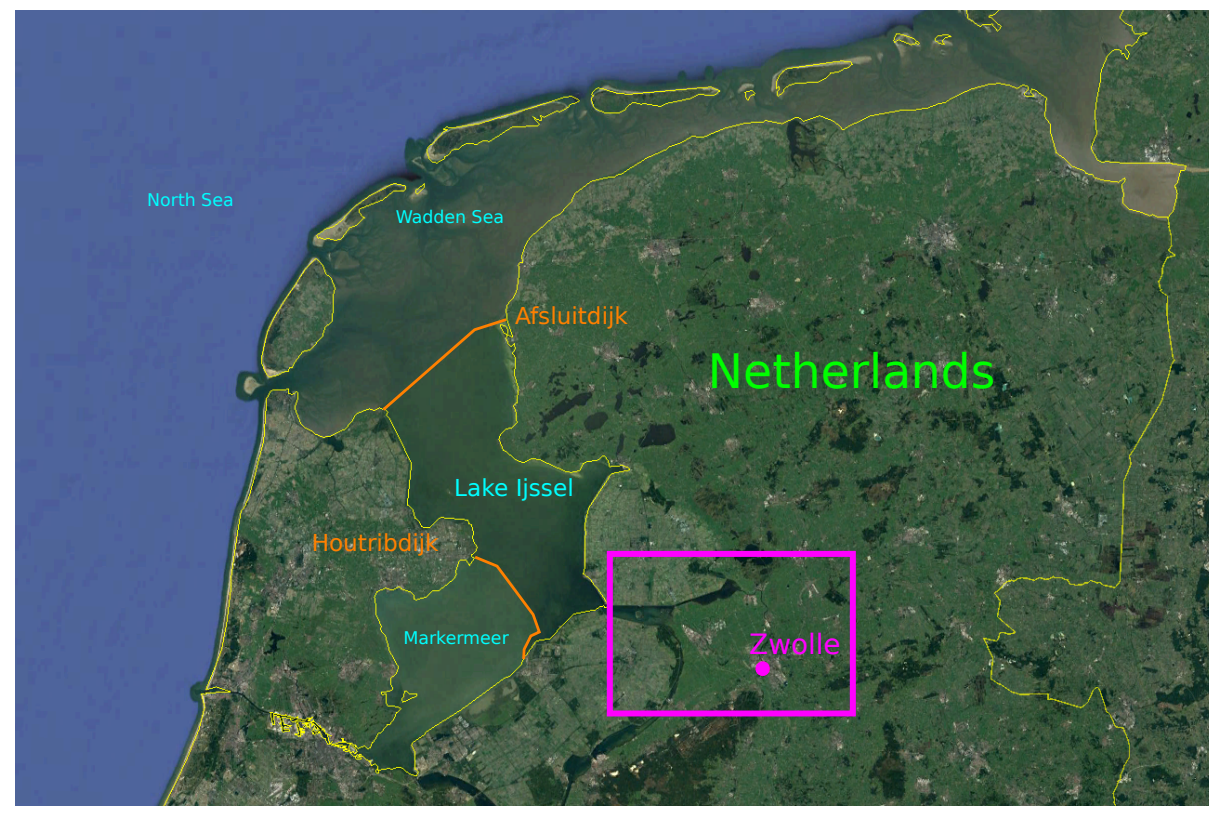

Figure 1: Map of the study area. In orange the dams that separate Lake IJssel from the Wadden Sea in the North and the Marker Lake in the South. In purple, the study area for the canals and rivers around Zwolle.

the city of Zwolle, for which the region is indicated in red. The targets vary in width between 30 and 170 meter, which is smaller than the delay/Doppler footprint. The water level in canals and rivers is controlled by locks, except for the Ijssel river. Therefore water-level variations are small and reach about three decimeters. Gradients are also limited to about $1 \mathrm{~cm} / \mathrm{km}$, which ensures low water-level interpolation errors between gauges. A list of gauges monitoring

60 the water bodies considered in this study is provided in the table 1. CryoSat-2 passed about 145 times over the study area around Zwolle.

\section{Data and Methods}

This section describes the gauge and CryoSat-2 data processing. The first part describes the CryoSat-2 full bit rate data in detail. The second part pro65 vides an overview of the CryoSat-2 FF-SAR processing and retracking. The 
Table 1: Interpolation technique and gauge measurements used for the lake, rivers and canals. The location of the gauges is given up to a kilometer precise.

\begin{tabular}{|c|c|c|c|c|c|}
\hline Target & Width $[\mathrm{m}]$ & Interpolation & Gauge & lon $[\mathrm{deg}]$ & lat [deg] \\
\hline \multirow[t]{10}{*}{ Lake IJssel } & \multirow[t]{10}{*}{-} & \multirow[t]{10}{*}{ inv. dist. } & Den Oever & 5.05 & 52.93 \\
\hline & & & Meetpaal 02 & 5.57 & 52.75 \\
\hline & & & Meetpaal 09 & 5.49 & 52.80 \\
\hline & & & Meetpaal 47 & 5.24 & 52.91 \\
\hline & & & Meetpaal 48 & 5.11 & 52.87 \\
\hline & & & Meetpaal 49 & 5.12 & 52.88 \\
\hline & & & Lake Ketelmeer West & 5.64 & 52.61 \\
\hline & & & Kornwerderzand & 5.34 & 53.07 \\
\hline & & & Krabbersgat & 5.28 & 52.69 \\
\hline & & & Lemmer & 5.71 & 52.84 \\
\hline \multirow[t]{3}{*}{ Kampen-Zwolle } & \multirow[t]{3}{*}{175} & \multirow[t]{3}{*}{ linear } & Kampen Bovenhaven & 5.93 & 52.55 \\
\hline & & & Katerveer & 6.05 & 52.51 \\
\hline & & & Keteldiep & 5.85 & 52.58 \\
\hline \multirow[t]{3}{*}{ Zwolle-Genemuiden } & \multirow[t]{3}{*}{80} & \multirow[t]{3}{*}{ linear } & Spooldersluis & 6.06 & 52.51 \\
\hline & & & Zwartsluis buiten & 6.08 & 52.64 \\
\hline & & & Genemuiden & 6.03 & 52.64 \\
\hline \multirow[t]{2}{*}{ Zwartsluis-Meppel } & \multirow[t]{2}{*}{50} & \multirow[t]{2}{*}{ linear } & Galgenkampsbrug & 6.18 & 52.70 \\
\hline & & & Meppelerdiep & 6.09 & 52.65 \\
\hline \multirow[t]{2}{*}{ Meppel-Rogat } & \multirow[t]{2}{*}{50} & \multirow[t]{2}{*}{ mean } & Galgenkampsbrug & 6.18 & 52.70 \\
\hline & & & Meppelerdiep & 6.09 & 52.65 \\
\hline Hasselt-Vilsteren & 35 & mean & Vechterweerd & 6.21 & 52.52 \\
\hline Star of Zwolle & 40 & mean & Spooldersluis & 6.06 & 52.51 \\
\hline
\end{tabular}

third part addresses the gauge data interpolation and the reference system transformation.

\subsection{CryoSat-2 full bit rate data}

Over the North, of the Netherlands CryoSat-2 operates in SAR mode. In this mode, CryoSat-2 transmits pulses in bursts of 64 . It receives the echoes of those pulses before the next burst is transmitted. The Pulse Repetition Frequency (PRF) is $18181.818 \mathrm{~Hz}$, while the Burst Repetition Frequency (BRF) is $84.796335 \mathrm{~Hz}$. During an overpass of CryoSat-2, a target on the ground track is illuminated for about 2 seconds, which corresponds to 180 bursts. This implies that coherent processing can be applied to $64 \times 180$ echoes. As resolution is inversely related to integration time, this enhances the along-track resolution. In this case, it yields the resolution of approximately $0.5 \mathrm{~m}$ in FF-SAR processing.

The echoes are deramped on receive, i.e. they are mixed with a replica signal, which is generated at the approximate time the return signal is expected, and subsequently low-pass filtered. After deramping, the frequency of the signals 
in the echoes is a function of time offset from the generation of the replica signal. The two-way travel time of the signals can be converted to range using the speed of light. Each echo is sampled into 128 complex values, representing a pulse length $\tau=44.8 \mu \mathrm{s}$ and a $320 \mathrm{MHz}$ chirp bandwidth. As frequency is 85 related to range, a waveform can be computed from the echoes using a discrete Fourier transform over the 128 complex values. At $320 \mathrm{MHz}$, the resolution of the waveform is $3.125 \mathrm{~ns}$ in two-way travel time, or approximately $0.47 \mathrm{~m}$ in range.

For each burst of echoes the ellipsoidal height, the latitude and the longitude of the satellite are provided. Additionally, the window delay is required, which provides the time between the transmission of the pulse and the generation of the replica signal. If the window delay is converted to tracker range, it refers to the range at bin 63 of the waveforms.

\subsection{Data processing}

This section discusses separately the FF-SAR processing and the range computation by means of waveform retracking.

\subsubsection{FF-SAR processing}

For the L1a-L1b processing, that is the computation of waveforms from the FBR data, we implement a variant of the backprojection algorithm described in

Egido $\mathcal{G}$ Smith [10]. Several adjustments are made to make the method work for CryoSat-2 data and the algorithm is tailored for inland waters in the Netherlands.

\section{Compute surface locations}

105 The integration time is limited to 1.9 seconds, so that the along-track resolution is approximately $0.56 \mathrm{~m}$. This ensures that we will not use data outside of the beamwidth when we do not account for changes in the pitch of the satellite and most natural scatterers are only visible during a fraction of the integration time anyway. The along-track resolution is used to generate a set of focal points on 
the ground track of CryoSat-2 by interpolating the latitude and longitude of the provided burst locations. Since the terrain in the Netherlands is nearly flat, second-order functions are fitted to the satellite altitude and the tracker range, from which a smooth reference elevation is computed through the focal points. The smooth reference surface is used to compute the ranges to burst and enalong track as a consequence of window delay (tracker range) changes. This way multi-looking can be performed over any number of along-track waveforms without having to take into account sudden movements of the leading edge. For a single focal point, 1.9 seconds of data is selected, which is around 160 bursts and about 10000 echoes. Using the provided burst locations, we compute the range between the burst center at satellite altitude and the focal point on the ground track. Then a time vector for the echoes is generated using a constant BRF and the PRF, which in turn is used to interpolate these ranges to the pulse locations. This interpolation also overcomes the issues of an unsteady burst datation in the data and the limited precision of the satellite positions [23. These ranges $R_{i}$ can be converted to what Egido $\&$ Smith [10] refers to as slow time, i.e. the time between echoes. The time between samples in an echo, with $j$ running from 0 to 127 , is refered to as fast time, so that we have an interval of $d t=\tau / 128 \mu s$ and $t_{0}=-63.5 d t$

\section{Range cell migration and range compression}

Before the Range Cell Migration Correction (RCMC), we apply Hamming win35 dows over the bursts in order to suppress spectral leakage [24]. The RCMC ensures that the signals in the 0.56 meter strip are aligned in the $\sim 10000$ waveforms ([10], figure 3). Note that after reading the full-bit rate data in Matlab, the phase corrections for CryoSat-2 are the complex conjugates of those presented by the theoretical description of Egido $\&$ Smith [10]. We apply the RCMC in a two-step process, which contains a geometrical range correction and a correction 
for window-delay variations. The geometrical RCMC is given as

$$
\Phi_{R C M C}=\exp \left(-2 \pi i \alpha\left(2 \frac{R_{i}-R_{0}}{c}-f_{D, i}\right) t_{j}\right)
$$

with $R_{0}$ the nadir reference range. The term $f_{D, i}$ represents the Doppler term as given by Egido $\&$ Smith [10] and $\alpha$ is the frequency slope of the transmitted chirp, which can be computed by dividing the chirp bandwidth by the pulse

length. The RCMC is applied by simply multiplying it with the 128 samples $j$ in the $\sim 10000$ received echoes $i$. The phase correction for the window-delay variations during the integration time is given as

$$
\Phi_{w d}=\exp \left(-2 \pi i \alpha\left(2 \frac{R_{t r, 0}-R_{t r, i}}{c} t_{j}\right)\right.
$$

with $R_{t r, i}$ the tracker range for echo $i$ and $R_{t r, 0}$ a reference tracker range. If the RCMC is implemented in this way, the resulting phase history would exhibit a remaining parabola as can be shown with transponder overpasses, which implies that the target is not properly focussed. The remaining parabola is likely related to an offset of the window-delay. One way to compensate for this is by introducing an offset of $0.67 \mu s$ in $t_{j}$ for the RCMC. After the RCMC, the waveforms are zero-padded and a discrete Fourier transform is applied for range compression.

\section{Focussing}

In contrast to the Residual Video Phase (RVP) and Residual Range Phase (RRP) correction as applied in Egido 8 Smith [10], we use a single range history

for all range bins. Hence, the RVP correction we apply reads

$$
\Phi_{R V P}=\exp \left(2 \pi i \frac{\alpha}{2}\left(2 \frac{R_{i}-R_{t r, i}}{c}\right)^{2}\right)
$$

and the RRP correction

$$
\Phi_{R R P}=\exp \left(2 \pi i f_{c} \frac{2\left(R_{i}-R_{t r, i}\right)}{c}\right),
$$

where $f_{c}$ is the carrier frequency of $13.575 \mathrm{GHz}$. Using a single range history for the RRP and the RVP has the consequence that signals across-track are 
not perfectly in focus. For water surfaces this has no significant consequences, because they either decorrelate or are only visible in a fraction of the integration time.

\section{Phase jumps}

After the RRP another step is required to focus the data. In transponder overpasses, it is visible that the phase exhibits $\frac{\pi}{2}$ jumps after each burst. These

phase jumps can be countered using a simple phasor $\exp \left(-\frac{\pi}{2}\left(N_{i}-1\right)\right)$, where $N_{i}$ is the burst number of echo $i$. An additional jump is present at the moment the window-delay changes. The amplitude of the additional jump depends on the way the window-delay offset is handled. Suppose that an offset to $t_{j}$ in Eq.

1751 only, phase jumps of approximately $1.1 \pi$ for each window-delay change of 12.5 ns are required to focus the echoes. A comparable phasor as for the burst phase jumps is applied, but in this case the phase is a function of the accumulated window-delay offset from the start of the integration time.

\section{Waveform computation}

After the phase corrections, the $\sim 10000$ complex echoes are coherently summed. The waveform is then computed as the squared absolute value of this coherent sum. The focal point can be moved along-track by introducing a linear phase change before summation. Phase changes of an integer number of $2 \pi$ over the integration time lead to independent waveforms. Using the phasor $\exp \left(-2 \pi n t_{i} / T\right)$, with slow-time $t_{i}$ of echo $i$ and $T$ the integration time, we can focus on multiple focal points $n$, while not having to compute all previous phase corrections again. Therefore, we use this relation to compute waveforms for 50 focal points, to reduce computational costs.

\subsubsection{Water-level estimation}

For the L1b-L2 processing, that is the retrieval of geophysical parameters from waveforms, two types of retrackers are used. Over the lakes, where it is expected that at least part of the waveforms resemble an ocean signal, the 
SAMOSA+ retracker is applied [9] as well as a threshold retracker [8]. In the application of the SAMOSA+ retracker, we estimate four parameters at the same time. We test various threshold retrackers to find the threshold that minimizes the variance of the obtained water levels (the statistics are shown in the appendix). Over the rivers and canals, we expect the waveforms to be more specular than ocean waveforms, so only a threshold retracker is applied. The threshold for these small targets is set to $60 \%$, because it has the smallest water-level variance over Lake IJssel (see section 4.1). The range between the satellite and the surface is computed by adding the retracker correction (i.e., the offset of the leading edge from bin 63) to the tracker range. Geophysical corrections are interpolated and then applied to the range as described in the ${ }_{205}$ Cryosat Product Handbook [3]. These do not include therefore the dynamic atmosphere and ocean tide corrections. The ellipsoidal heights are computed by subtracting the corrected range from the satellite altitude.

For the lake-level estimates, the multi-looking is varied from 20 to 600 waveforms, which corresponds approximately to along-track distances from 10 to 300 meters. A bias and standard deviation of the water levels is computed. The first is expected to be nearly independent of the multi-looking, and the latter is expected to increase with decreased multi-looking. Over rivers and canals, multi-looking is applied over the approximate river width and for the ditches single-look waveforms are retracked.

215

Data editing is applied for the lake-level estimates to remove land contaminated measurements to be able to better quantify the effect of an increased number of independent looks as compared to delay/Doppler processing. The first criterion is the pulse peakiness, which is defined as the ratio between the maximum power and the mean power of the waveform. In case we use the 220 SAMOSA + retracker, we also set a threshold on the waveform fit, expressed as the root-mean-square of differences between the received waveform and the model fitted in retracking. 


\subsection{Gauge data interpolation and referencing}

The in-situ data are obtained from the publicly available Rijkswaterstaat water level database, which contains gauge data in the Netherlands (https: //waterinfo.rws.nl/\#!/kaart/waterhoogte-t-o-v-nap/). For each gauge, we obtained time series spanning the period 2010-2019, with a sampling interval of 10-30 minutes. In case of data gaps, water levels are interpolated linearly in time up to a maximum of 12 hours from the nearest data point. For the lakes, the median water level and its standard deviation based on the Median Absolute Deviation (MAD) method [5] are computed for each epoch. Water levels outside three standard deviations from the median are removed from the analysis, to ensure problematic measurements and offsets are removed. The outlier removal procedure is not applied for gauges in rivers and canals, because there are not enough observations.

The geographic correlation scales in the water bodies are unknown and impossible to derive accurately from the gauge data alone, and so we use a simple inverse distance weighted average to compute a grid of water levels, such that

$$
w l_{i}(t)=\frac{\sum_{1}^{G} d_{g i}^{-1} w l_{g}(t)}{\sum d_{g i}^{-1}}
$$

where $w l_{i}(t)$ and $w l_{g}(t)$ are the interpolated and observed water levels at time $t$, and $d_{g i}$ is the distance between the gauge and the grid cell. For a river section, vectors of water levels are computed over a polyline representing the center of the stream, which are either linearly interpolated or the mean is taken depending on the number of available gauges. As the water-level fluctuations are small and the interval is only 10 minutes, nearest-neighbour interpolation is used in time. Further details on the interpolation methods are given in a table in the appendix.

Additional validation data is obtained for the water-level estimates in ditches. To show that we can separately estimate water levels in a canal and two nearby ditches, historical data of the Overijssels Canal are made available by the Waterboard Drents Overijsselse Delta (WDO Delta) (Johan Schadenberg, WDO 
Delta, personal communication, May 28, 2019). For the ditches no historical water levels are available, but the minima and maxima of the groundwater control levels are available from https://wdodelta.maps.arcgis.com/apps/ InformationLookup/index.html?appid=03b006f6edac416f97c52c96142f $7 f 6 a$. 22

\section{Results and discussion}

This section is split into three parts. In the first part we show the results over Lake IJssel in which we discuss the effect of multi-looking on the standard deviation of the water levels estimated with the SAMOSA+ and threshold retrackers. We will also address the issue of waveform contamination and show how filtering on pulse peakiness and waveform fit can help to mitigate these issues. The second part discusses the results over rivers and canals with varying widths, which validates water levels of targets smaller than the Fresnel zone. In over ditches of several meters wide.

\subsection{Lake IJssel}

The top-left panel of figure 2 shows the differences between water levels derived from multilooked FF-SAR waveforms and interpolated gauge measure- 
ments over Lake IJssel. The differences between the water-level observations are on the order of several centimeters for Lake IJssel. This implies that our validation method properly captures geoid slopes [16, 15] and wind effects, that cause differences of more than a meter between gauge measurements. In satellite altimetry validations where only a single gauge per lake is used, the uncertainty of the altimetry measurement might be overestimated. Note that still some large, primarily negative, outliers can be identified. Negative means that the range towards the surface is overestimated. The outliers are clustered and can be found primarily close to the shores near small neighbouring lakes, near harbours and near a small artificial island. These targets typically exhibit smaller waves, resulting in specular reflections and large peaks in the waveforms. If the target is located across track, it is further away from the satellite than nadir and its signal manifests itself in the tail of the waveform. This results in an increased range, hence an underestimation of the water level. To filter specular reflections, we apply an upper threshold on the pulse peakiness [17] of 12. Additionally, some waveforms have more than one peak of which the magnitudes are at the same order. This can occur for example near the Afsluitdijk, which is the dike cutting off the Wadden Sea from Lake IJssel, where reflection from both water bodies are present. Therefore, we set a threshold of 4 on the waveform fit as done in Dinardo et al. [9]. After applying these data editing steps, we obtain the water-level differences shown in the top-right panel of figure 2

After data editing, we are able to compute an accurate bias and investigate how the precision changes as a function of along-track multi-looking distance. The bias is estimated as the median of all altimetry-gauge differences in Lake IJssel, and the standard deviation is estimated as $1.4826 \times M A D[\underline{5}$, where the $M A D$ is the median of absolute deviations. The standard deviation should be an indication for the repeatibility, or accuracy, once the measurements are corrected for the bias. To provide an estimate of precision of the retrackers, the standard deviation is also computed per pass and then the mean and median are taken over all the passes. The results for various degrees of multi-looking are given in table 2 , which also contains similar statistics for the retracked ESA 

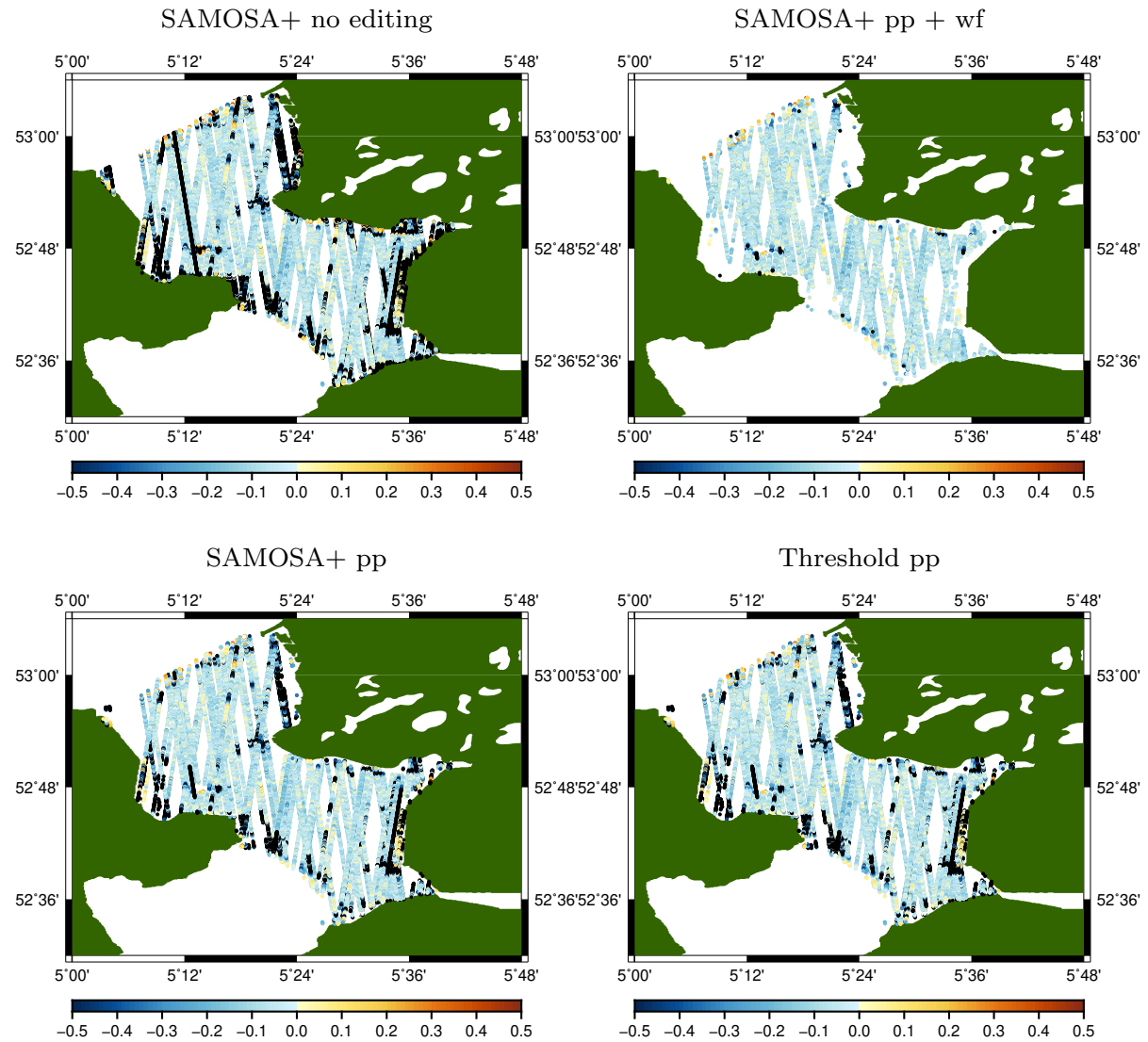

Figure 2: Differences [m] between interpolated gauge water-levels and CryoSat-2 estimates over Lake IJssel. Multilooking of 100 waveforms is applied. Data editing on pulse peakiness (pp) and waveform fit (wf) is applied.

L1b Delay/Doppler product.

The first set of three columns in the table show the bias as a function of multilooking. Compared to the Delay/Doppler waveforms there is a small difference in bias of $1.8 \mathrm{~cm}$ at $300 \mathrm{~m}$ multi-looking. This is possibly related to the reported difference in waveform shape between FF-SAR and Delay/Doppler waveforms [10]. Besides there is a slight trend in bias as a function of multi-looking. We argue that this is related to the lower signal-to-noise ratio at smaller multilooking distances, which makes the leading edge of the waveform more difficult 
to identify. For comparison between the SAMOSA+ and threshold retrackers, we only remove waveforms with high pulse peakiness in the other two columns (the remaining observations are shown in the bottom panels of figure. 21). Not editing on waveform fit means that several multi-peaked waveforms enter the analysis and produce a noisier result, which changes the bias slightly. The threshold retracker, which strongly relies on the shape of the leading edge, is likely to be more sensitive to speckle, which can cause the bias to increase. This is explained as follows. We can assume that the leading edge is steep for inland waters, as the waves are generally small. Destructive interference cannot occur on the bins before the leading edge as no signal is received, so the $60 \%$ threshold will never be reached before a signal is received from the surface. However, if bins in the leading edge suffer from destructive interference, the threshold of $60 \%$ is reached later and the range will increase.

In the second set of three columns the standard deviations of all water-level differences (between altimeter height and gauge height) over Lake IJssel are computed. When applying SAMOSA+ retracking in combination with data editing based on pulse peakiness, we obtain values decreasing from $11.4 \mathrm{~cm}$ for $10 \mathrm{~m}$ multi-looking to $4.6 \mathrm{~cm}$ for $300 \mathrm{~m}$ multi-looking. The standard deviation associated with the Delay/Doppler estimates compares to an averaging distance of the FF-SAR waveforms of 100 meters, which indicates a three-times increase of the number of independent looks. The standard deviation of the SAMOSA+ and threshold retrackers are quite comparable if only a pulse-peakiness filter is applied. This does not directly indicate that the threshold retracker is at the same level of accuracy as the SAMOSA+ retracker, but the SAMOSA+ retracker has some problems tracking noisy and double-peaked waveforms. Over the ocean a threshold retracker is also likely to diverge as the waves get higher, which is not the case over a lake.

The precision is defined as the standard deviation of the water levels within a pass. The average of these standard deviations is given in the last three columns. It should be smaller than the standard deviations discussed before as they do not contain inter-track errors related to geophysical correction and 
Table 2: Bias, standard deviation and precision estimates for the SAMOSA+ retracker (S) and the threshold retracker $(\mathrm{T})$ after editing on pulse peakiness $(\mathrm{pp})$ and waveform fit (f). The equivalent distance is an approximation of the multi-looking distance, but should not be interpreted as the resolution over non-coherent targets like water. The precision is computed in the conventional way with respect to the mean and using the MAD, which are separated in the last columns with a ' $/$.

\begin{tabular}{cc|ccc|ccc|ccc}
\hline $\begin{array}{c}\text { no. of } \\
\text { wav. }\end{array}$ & $\begin{array}{c}\text { multil. } \\
{[\mathrm{m}]}\end{array}$ & \multicolumn{3}{|c}{ bias $[\mathrm{cm}]$} & \multicolumn{4}{c}{ std $[\mathrm{cm}]$} \\
\hline 20 & 10 & -7.6 & -10.9 & -11.6 & 11.4 & 15.2 & 14.8 & $10.8 / 9.5$ & $14.0 / 22.6$ & $14.2 / 17.2$ \\
50 & 25 & -7.0 & -8.6 & -8.6 & 8.1 & 10.2 & 10.3 & $7.5 / 6.9$ & $9.3 / 16.9$ & $9.5 / 12.0$ \\
100 & 50 & -6.5 & -7.7 & -6.9 & 6.2 & 7.8 & 7.9 & $5.4 / 5.0$ & $6.6 / 13.5$ & $7.2 / 9.7$ \\
200 & 100 & -6.3 & -7.3 & -5.9 & 5.2 & 6.7 & 6.5 & $4.4 / 4.0$ & $5.4 / 12.2$ & $5.7 / 7.5$ \\
300 & 150 & -6.3 & -7.2 & -5.6 & 5.0 & 6.4 & 5.8 & $4.1 / 3.7$ & $4.9 / 11.3$ & $5.1 / 5.4$ \\
600 & 300 & -6.2 & -6.9 & -5.1 & 4.6 & 5.8 & 4.8 & $3.5 / 3.1$ & $4.2 / 10.2$ & $3.9 / 4.3$ \\
d/D & 300 & -8.0 & -9.2 & -6.3 & 5.4 & 7.2 & 7.1 & $4.4 / 4.0$ & $5.7 / 11.8$ & $6.3 / 6.9$ \\
\hline
\end{tabular}

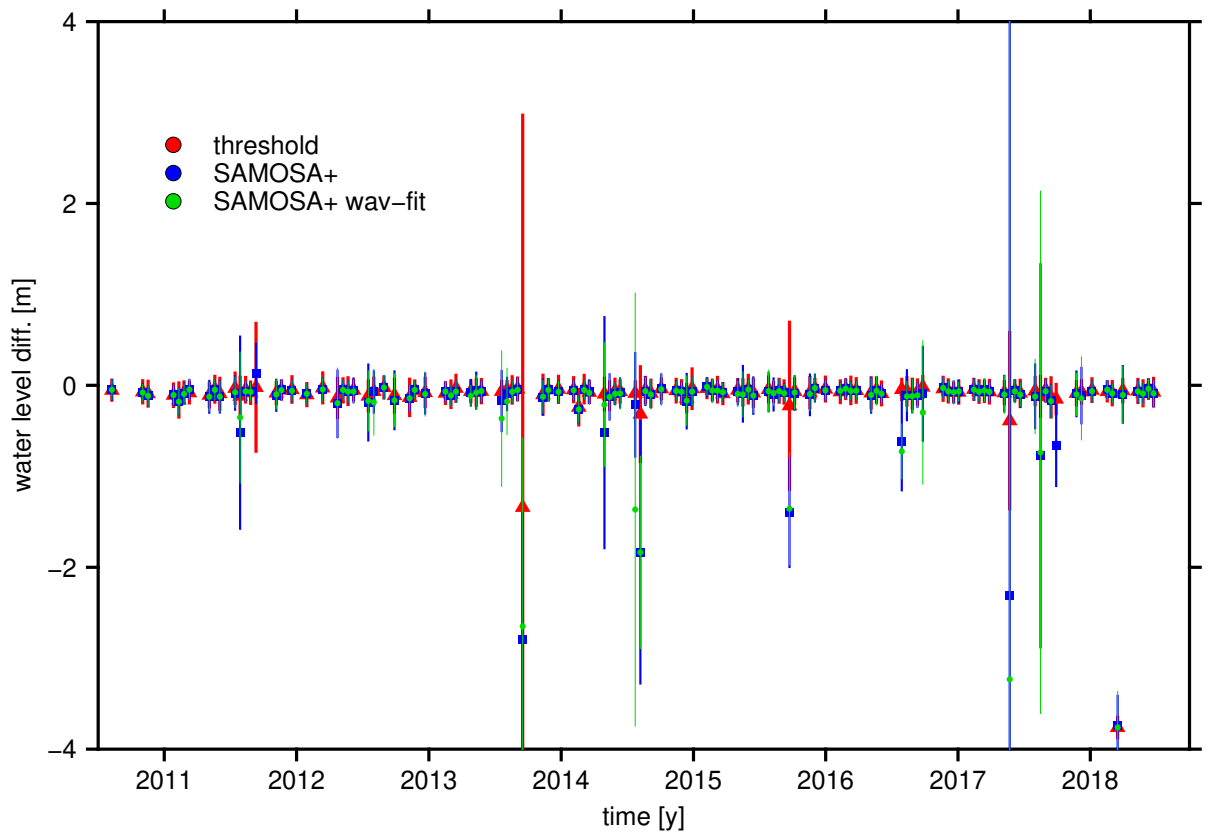

Figure 3: Time series of differences $[\mathrm{m}]$ between CryoSat-2 and gauge water levels for Lake IJssel. Multilooking of 100 waveforms is applied. Pulse-peakiness filtering is applied in all cases. The time series based on the threshold retracker, the SAMOSA+ retracker and the SAMOSA+ retracker with additional waveform-fit filtering are shown in red, blue and green, respectively. 
long-wavelength orbit differences between tracks. We computed the precision using the $1.4826 \times M A D$, which is less prone to outliers and should reflect the precision for a open ocean track. We additionally computed the precision in the conventional way, such that it reflects the precision over water bodies, where waveform contamination occurs. Precision is primarily important for geodetic purposes, like gravity field determination where along-track slopes are required. A 300 meter multi-looking distance ensures a precision improvement of more than $0.5 \mathrm{~cm}$ with Delay/Doppler. For geodetic purposes, waveform fit editing is in these cases also essential, as they ensure a similar size improvement with respect to only pulse-peakiness editing. Note that both of the standard deviations are close to similar if waveform-fit editing is applied. In case it is not, the values for the two ways of computing the precision diverge, which indicate a substantial number of outliers are present in some tracks after data editing on pulse peakiness only. The presence of outliers is confirmed by the uncertainty bars of the time series in figure 3 .

The time series in figure 3 indicate stability in the water level estimates as virtually no drift is present. The absence of a drift is supported by validation results over a transponder [14]. There are, however, outliers present in the time series, which are the effects of targets with flat water surfaces as discussed before. Editing on the pulse peakiness only is not sufficient to deal with these targets. In case it is not possible to filter on waveform fit, the threshold retracker appears to be more robust i.e., it yields fewer outliers. Note that in any case, less than $10 \%$ of outliers are present and therefore an iterative three-sigma outlierremoval scheme suffices to clean the time series. Lake IJssel is a worst-case scenario for a lake of its size $\left(1100 \mathrm{~km}^{2}\right)$, as it is surrounded by many other water bodies, harbours and other waveform-polluting targets. For smaller lakes in this part of the Netherlands, like Lake Ketelmeer and Lake Zwartemeer, building a time series becomes more problematic due to waveform pollution in almost every measurement (see appendix). Robust lake-level estimation in these lakes requires more complex filtering strategies or multipeak or subwaveform retracking, which is beyond the scope of this paper. 


\subsection{Rivers and canals}

The rivers in the area around the city of Zwolle (see figure 4) are gauged at several locations. The maximum width of the rivers and canals is approximately 170 meters, which is about half the size of the Delay/Doppler footprint in the along-track direction. In comparison with lakes, we expect a large peak power as the surface is smoother. Therefore, reflections are qausi-specular. No data editing based on pulse peakiness of waveform is applied. A threshold retracker is used to estimate the range.

Figure 4 shows the differences between the FF-SAR-derived water levels and the interpolated gauge measurements. The statistics for the individual canals and rivers are listed in table 3 . The bias is estimated as the mean and the median, to make a distinction between a bias estimate including and excluding outliers. For rivers not surrounded by other strong scattering surfaces, we expect both the mean and the median bias to be similar. Over the Netherlands, the absolute value of the mean bias is in most cases larger, as a substantial amount of off-nadir scattering is present. The median bias should therefore be close to the one found over Lake IJssel, which is for four-out-of-six segments the case. As expected, the mean bias is only close to the one found over Lake IJssel in two segments. In the river sections Zwartsluis-Meppel and Hasselt-Vilsteren, both the absolute values of the median and the mean are substantially larger than over Lake IJssel. Note that the differences are at the decimeter level, which indicates a substantial amount of reflections from cross-track targets within the pulse-limited footprint $(\approx 1 \mathrm{~km}$ radius $)$. Figure 4 shows that clusters of more negative values are present in these two segments, where many small ponds and lakes surround these rivers. As the range difference to the river is small this issue cannot be solved using multi-peak retracking.

Some positive outliers also occur, but they are fewer in number and therefore hardly affect the estimated offset. Positive outliers indicate reflections of targets that are elevated with respect to the river and occur mostly in the KampenZwolle section of the Ijssel river. The Ijssel river is surrounded by multiple water bodies within its dikes. Most of these positive outliers are at the decime- 


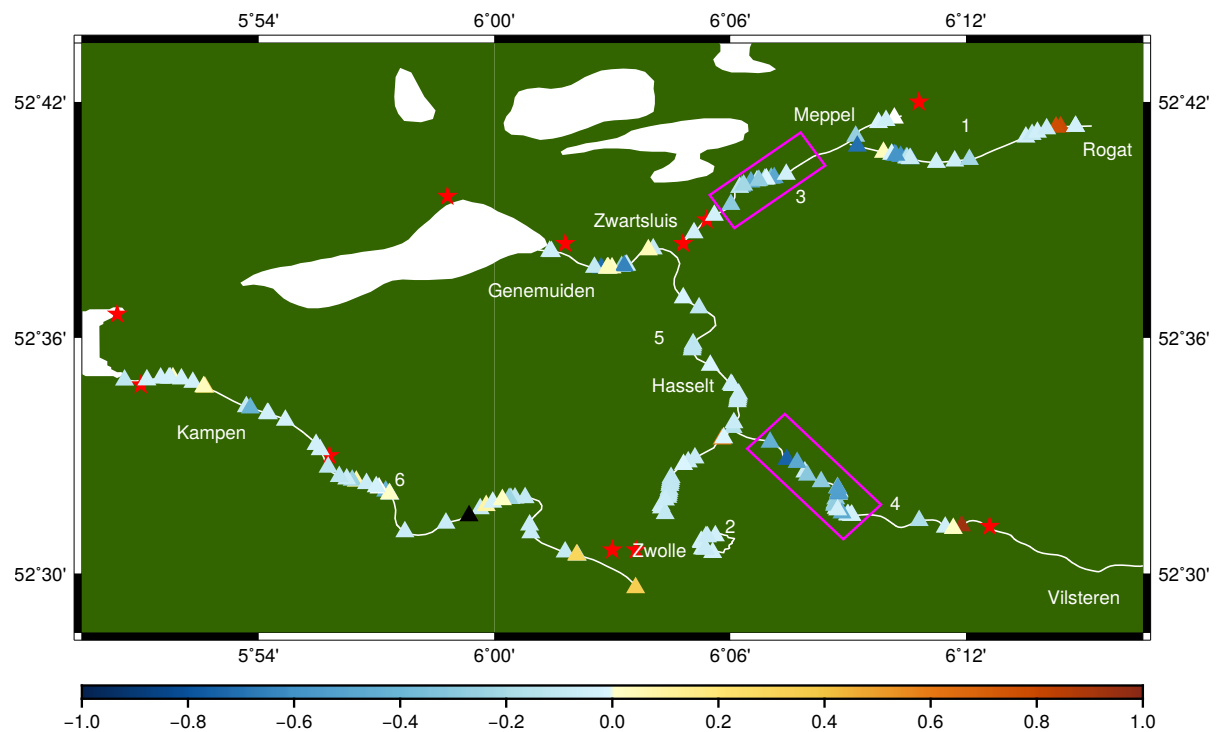

Figure 4: Differences $[\mathrm{m}]$ between interpolated gauge and CryoSat-2 water-level estimates over the rivers and canals. The stars indicate the locations of gauges and the numbers indicate the segments as given in table 3 The pink boxes indicate two clusters of negative values.

ter level, so as for the negative outliers a multi-peak retracker will not resolve two elevations. The largest positive outliers are about 1 meter and occur in the Meppel-Rogat, Hasselt-Vilsteren and Kampen-Zwolle sections. Most of these waveforms of the other outliers are multi-peaked, which can potentially be handled during retracking. It requires external information about the water levels to determine which peak belongs to the river section.

As for the lake, the standard deviation is computed in two ways (using the MAD and as the deviation from the mean). In absence of outliers, the distribution of water-level differences is expected to be normal and both numbers will be similar. However, in most cases the MAD-based standard deviation is smaller than the standard deviation computed with respect to the mean, which indicates a non-normal distribution caused by outliers. Note that the MAD is large for the sections of rivers where the median bias deviates most from zero. This indicates that a substantial amount of water-level estimates is affected by surrounding targets. For the three sections Kampen-Zwolle, Zwolle- 
Table 3: Bias and standard deviations of CryoSat-2 and gauge water-level differences. The standard deviation (std) is computed as $1.4826 \times M A D$ with respect to the median and in the conventional way with respect to the mean (standard).

\begin{tabular}{lc|ccc}
\hline River segment & Mult. & bias median/mean $[\mathrm{cm}]$ & std MAD/standard $[\mathrm{cm}]$ & NoM \\
\hline 1. Meppel-Rogat & 70 & $-8.2 /-18.0$ & $15.4 / 39.7$ & 23 \\
2. Star of Zwolle & 80 & $-5.0 /-5.5$ & $2.0 / 1.6$ & 9 \\
3. Zwartsluis-Meppel & 100 & $-15.3 /-10.1$ & $18.2 / 43.9$ & 18 \\
4. Hasselt-Vilsteren & 100 & $-18.2 /-18.9$ & $21.5 / 29.8$ & 29 \\
5. Zwolle-Genemuiden & 160 & $-7.3 /-8.1$ & $3.8 / 16.7$ & 48 \\
6. Kampen-Zwolle & 350 & $-6.1 /-13.1$ & $5.8 / 74.3$ & 45 \\
\hline
\end{tabular}

Genemuiden and Star of Zwolle the MAD is below one decimeter. For the Star of Zwolle and Zwolle-Genemuiden sections, the MAD-based standard deviation is even smaller than the numbers obtained for the accuracy at equivalent multilooking distances over Lake IJssel. The low standard deviation of water-level differences in the Star of Zwolle section can be explained by the absence of other water bodies across track. In combination with the specular returns, this yields a large signal-to-noise ratio. Between Zwolle and Genemuiden there are several surrounding lakes, but they are connected to the river system, so they are at the same water level. Besides that, most of these lakes are within the pulselimited footprint and therefore at a comparable range. The standard deviations computed with respect to the mean are significantly larger. Note that a single outlier of 1 meter in the Meppel-Rogat, Zwartsluis-Meppel and Hassel-Vilsteren regions, with the current number of water-level differences, already increases the standard deviation by a decimeter. The largest differences between the two ways of computing the standard deviation is at the Kampen-Zwolle section, where a single $5 \mathrm{~m}$ outlier is responsible for a large fraction of the $74 \mathrm{~cm}$. During postprocessing the outliers can be removed from the analysis.

\subsection{Ditches}

Arguably the most important advantage of FF-SAR with respect to delay/Doppler processing is the ability to detect very narrow water bodies. Egido 
E Smith [10] demonstrated that it is possible to detect lakes with a width of less than 40 meters, which is smaller than the Fresnel zone. In this section, we demonstrate that it is possible to detect ditches with a width of less than 5 meters, located less than 10 meters away from the canal, and to derive their water levels.

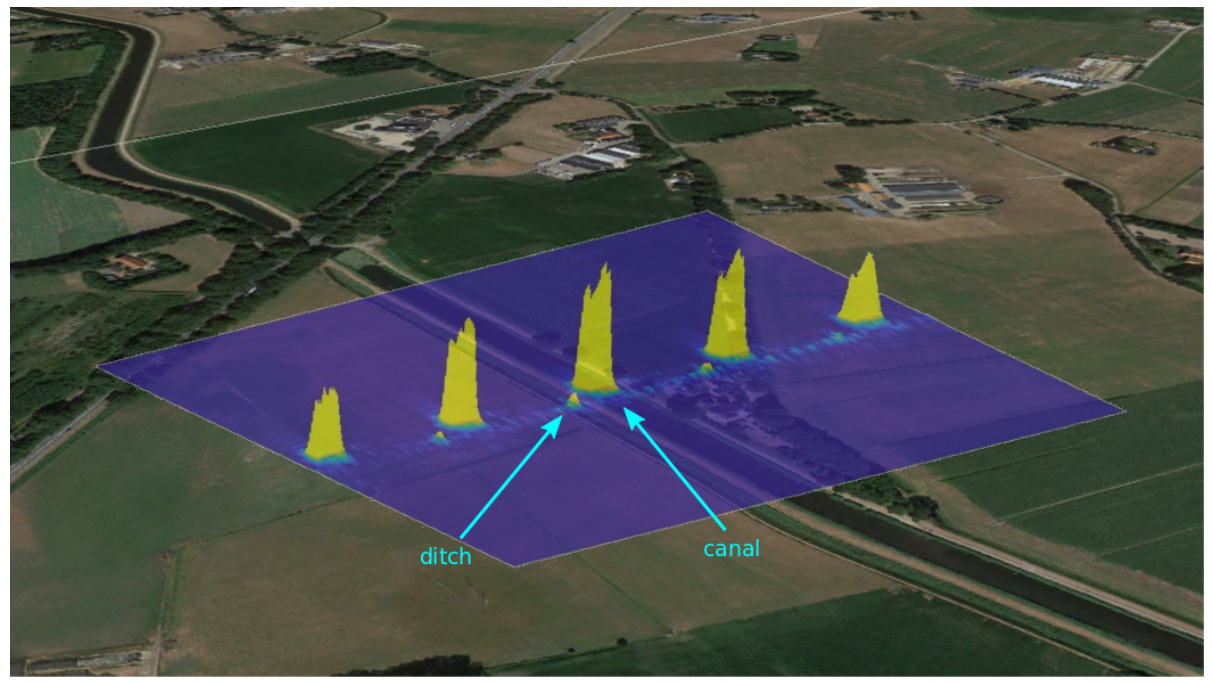

Figure 5: FF-SAR radargrams displayed at the crossing with the Overijssels Canal. The radargrams shows the main lobe and four aliases of the canal, which are present because of the closed-burst sampling of CryoSat-2. Next to the canal main lobe a signal from the neighbouring ditch is visible.

In figure 5 an along-track radargram is plotted over a Google Earth image. The "ghosts", or spatial aliases, caused by the closed-burst sampling of CryoSat2 are clearly visible and repeat every $\sim 90$ meters. The main lobe is positioned over a canal and has a width of almost 20 meters, which is slightly wider than the canal ( $\sim 18$ meters). Next to the large lobe a second signal is present, which is at an along-track distance of about 25 meters from the center main lobe and corresponds to a reflection from the nearby ditch. The ditch has a width of approximately 3 meters.

Several other tracks and waveforms over the same canal are shown in figure 6. A similar ditch is present near the tree line underneath the left pass (panel 

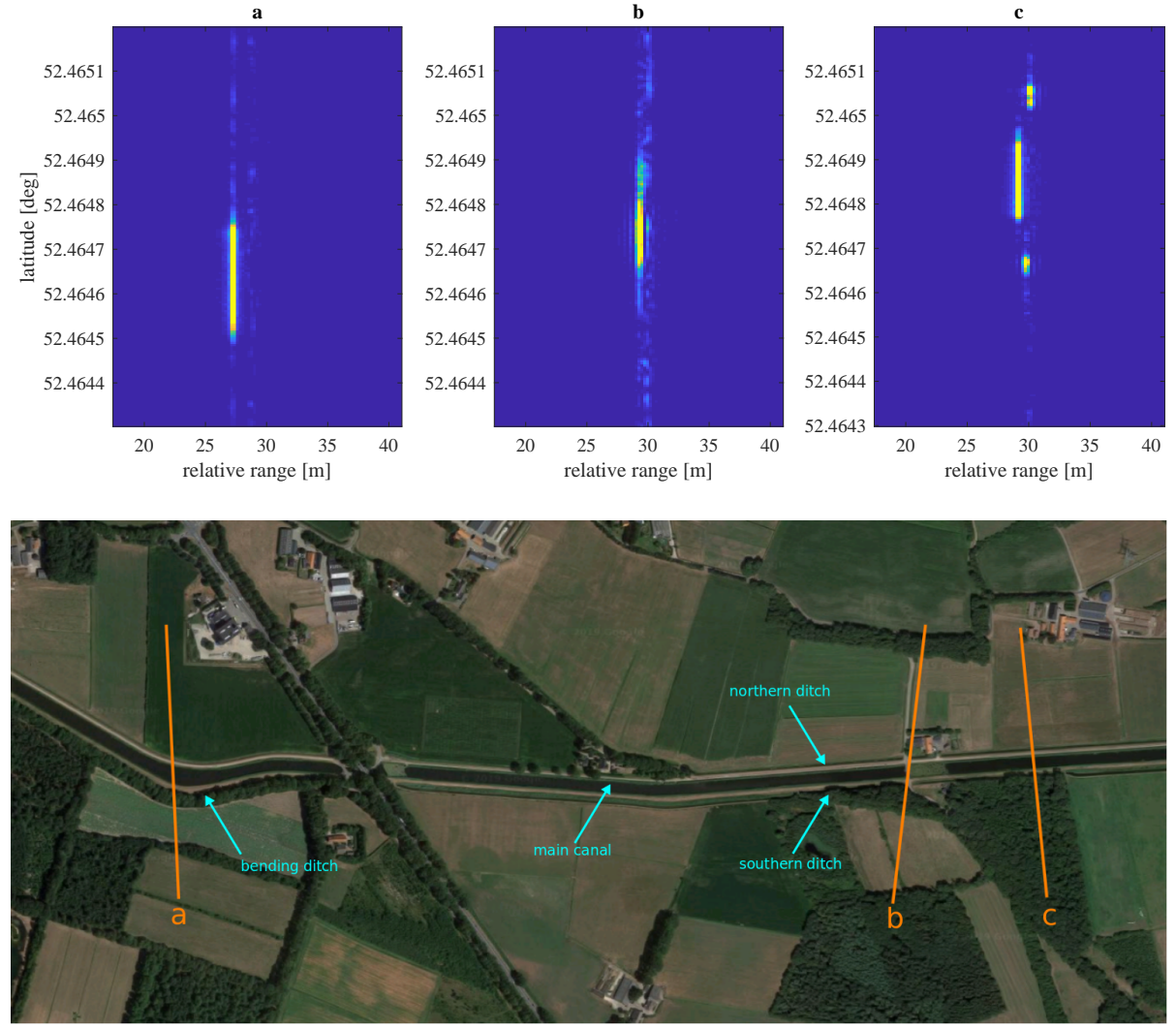

Figure 6: Zoom of radargrams around the main lobe of three tracks over the Overijssels Canal. The values are normalized range from 0 (blue) to 1 (yellow). Three crossing of Cryosat- 2 are visible: in a turn (a), non-perpendicular (b) and perpendicular (c).

a) over the canal, but we do not see any signal in the waveforms. This can at least partly be attributed to the bending of the ditch, which causes only a few meter of water to be present in the cross-track direction of the waveform. We also observe a wider lobe over the canal, which is a consequence of off-nadir reflections from the northward bending part of the canal that is not beneath the ground track. Note that the width of the lobe is only a few meters wider than in the lobes of the other passes, even though the canal is still close to the ground track. This indicates that the water surface is very flat so that primarily reflections in the first Fresnel zone contribute to the signal.

The second crossing (panel b) is near a bridge at a straight section of the 
canal with ditches on both sides. The descending satellite track is not perpendicular to the canal, so even though a strip is 0.5 meter wide in the along-track direction it covers the ditches and the canal. Therefore the signals coming from ditches on both sides of the canal end up in the same waveforms as the signal from the canal. If the signals are close to specular and the water level in the ditches is several meters lower than the water level in the canal then the signals should emerge at different locations in the waveform, with the ditch at greater range than the canal. The signals of the ditches are expected to be small, because a limited water area is exposed in the cross-track direction, due to the non-perpendicular crossing. A small signal can, however, still be distinguished with a slightly larger relative range. It is not possible to determine whether it comes from the North or the South side of the canal.

Panel c shows a radargram of a perpendicular pass. At this location ditches are present on both sides of the canal and the water levels in both ditches are below the water level of the canal. The ditches are almost perfectly aligned with the cross-track footprints, so the ditch signals represent a water surface of several tens of square meters. The power of the waveform peaks is therefore at a similar order as the main lobe of the canal.

As the ditch signals have a large signal-to-noise ratio, the single-look waveforms of the last pass can be retracked. In figure 7, the water levels estimated with a threshold retracker are shown. The along-track length covered in the figure is about 90 meter, which is not even a third of the Delay/Doppler footprint. The water level of the canal is visible in the middle and the ditches on the sides. For five tracks the bias, between CryoSat-2 and hourly-averaged WDO Delta gauge heights, ranged between -10.3 and $-7.1 \mathrm{~cm}$, which is in close agreement with the values obtained over the rivers and lake. The water level in the canal is kept about $0.7 \pm 0.1$ meter higher than the groundwater in area 456 , where the South side ditch is located, and about 1.0 \pm 0.1 meter higher than in area 486, where the North side ditch is located. A statistically equivalent difference is observed in figure 7

Note that the precision of the derived heights is at centimeter level. Since the 
waveforms are perfectly specular with a high signal-to-noise ratio, the precision is better than over Lake IJssel. If the uncertainty of the geophysical range correction is assumed to be several centimeters, the accuracy of the ditch water levels is better than a decimeter. With the current validation method, this can however not be proven. This is under near-perfect circumstances, with a ground track crossing the canal and the ditch almost at a $90^{\circ}$ angle. Deviations from $90^{\circ}$ decrease the signal-to-noise ratio and therefore the precision. The elevations of isolated targets in dry areas can possibly be determined at angles far from perpendicular, because even though the water signal becomes small, it might be larger than the signal from bare land.

\section{Conclusions}

We have described and implemented an FF-SAR backprojection algorithm to retrieve inland water-level estimates from CryoSat-2 data. Water levels have been retrieved for targets of various shapes and sizes, such as lakes, rivers/canals, and ditches. The ditches are by far the narrowest water bodies for which an elevation has been estimated with a satellite radar altimeter. The water levels of each target have been validated using the Dutch gauging network and groundwater control levels. As the gauges are benchmarked and connected to the national height datum, absolute water level validation is possible for the gauged targets. This is also the first time it is shown that satellite radar altimetry data can be used to estimate water levels in ditches of a few meters wide. The small ditches are not gauged and therefore only a relative validation ${ }_{525}$ is conducted using nearby water bodies.

The medium-sized Lake IJssel, has been used to determine the bias and precision of FF-SAR-derived water levels. Data editing has been applied based on waveform fit and pulse peakiness to remove waveforms contaminated by reflections from nearby targets. SAMOSA+ and threshold retrackers were used to derive the heights from the FF-SAR waveforms. A bias of approximately 6 centimeter is found using the SAMOSA+ retracker, which slightly differs from 


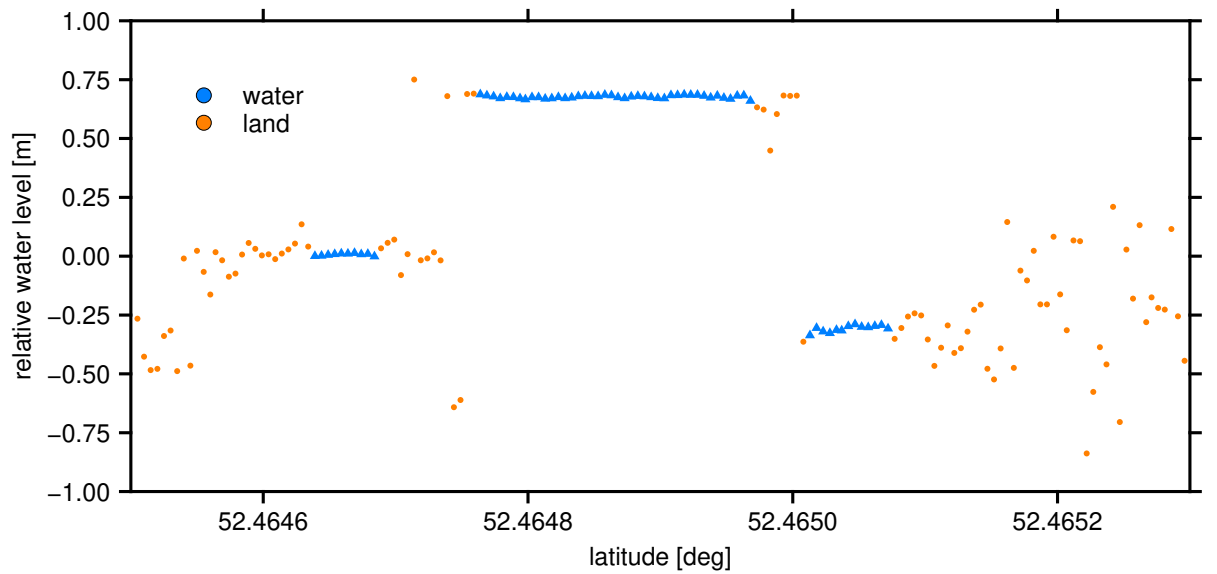

Figure 7: Relative water-level estimates (blue) of the Overijssels Canal and two neighbouring ditches. The water levels correspond to the waveforms of the perpendicular pass in figure 6 Classification based on waveform power is used to separate the canal and ditch measurements from those over land (orange).

the bias when using standard Delay/Doppler processed waveforms. A comparable bias is found by using a threshold retracker based on $60 \%$ of the maximum waveform power. The precision and accuracy of the individual water levels depend on the level of multi-looking and ranges between 10.8 centimeters for 10 meter averaging and 3.5 centimeters for 300 meter averaging. The performance in terms of precision and accuracy of delay/Doppler is comparable to FF-SAR at 100 meter of multi-looking, which corresponds to the approximate increase of the number of independent looks by a factor of three.

The FF-SAR-derived water levels of six river sections around the city of Zwolle have been validated. Multilooking over the river width is applied before a threshold retracker is used to derive the river level. A bias between the gauge measurements and CryoSat-2 water levels is found, that is comparable to the estimate over Lake IJssel. The standard deviation of water-level estimates ranges from two centimeters to several decimeters. The main driver for the magnitude of the standard deviation is not river width, but the amount of waveform pollution from surrounding targets. Several outliers ranging from decimeters to several meters are present. If multiple peaks are distinguishable, 
multipeak retrackers in combination with external information might help to a statement of policy, decision, or position on behalf of NOAA or the U. S. Government.

\section{Appendix}

This appendix contains a table with statistics for various threshold retrackers and a figure with additional results over small lakes. Table 4 lists the biases, 
standard deviations and precision for retrackers with a threshold ranging from 0.5 to 0.9 times the maximum power. As expected the bias depends strongly on the threshold. Also note that at higher thresholds (0.7-0.9) the bias increases substantially when the multi-looking decreases. At a threshold of 0.6 the bias is closest to the one obtained with the SAMOSA+ retracker. The relation between the threshold and the standard deviation and the precision is less obvious, but the best results are obtained with a threshold of approximately 0.6.

Figure 8 shows the results of FF-SAR in combination with the threshold retracker over Lake Ketelmeer and Lake Zwartemeer. For smaller lakes, like Lake Ketelmeer and Lake Zwartemeer, retracking and filtering becomes more problematic. Even though we can achieve high static along-track resolution, cross-track land pollution is present in almost any waveform in both lakes. Besides that, in the center of Lake Ketelmeer a water-cleaning facility in the form of an 800 meter ring is present, in which the water level is kept several meters lower than the surroundings. As a consequence, the unedited water-level estimates contain a large fraction of outliers. Data-cleaning procedures based on waveform and pulse peakiness are not suitable, because they eliminate almost all targets as shown in the right panel. Multi-peak waveform retrackers can help to retrack both the lake signal and the signals from surrouding targets. A more complex outlier-removal approach or external information about the approximate water height should be used to determine which signal in the waveform corresponds to the water surface. Note that the size and shape of the lake are not the only factors that determine the quality and complexity of water-level 600 retrieval. Waveforms from lakes of similar size and shape as Lake Ketelmeer and Lake Zwartemeer with dry surroundings can more easily be processed. 
Table 4: Bias, standard deviation and precision estimates based on various threshold retracker (T) after filtering on pulse peakiness.

\begin{tabular}{|c|c|c|c|c|}
\hline multi-looking & threshold & bias $[\mathrm{cm}]$ & std $[\mathrm{cm}]$ & precision $[\mathrm{cm}]$ \\
\hline \multirow[t]{5}{*}{20} & 0.5 & -1.4 & 14.6 & $13.9 / 16.6$ \\
\hline & 0.6 & -11.6 & 14.8 & $14.2 / 17.2$ \\
\hline & 0.7 & -21.1 & 16.6 & $15.7 / 20.1$ \\
\hline & 0.8 & -31.6 & 20.4 & $19.3 / 24.8$ \\
\hline & 0.9 & -45.5 & 27.6 & $26.1 / 33.0$ \\
\hline \multirow[t]{5}{*}{50} & 0.5 & 1.3 & 10.6 & $9.9 / 12.5$ \\
\hline & 0.6 & -8.6 & 10.3 & $9.5 / 12.0$ \\
\hline & 0.7 & -17.5 & 10.9 & $10.1 / 14.7$ \\
\hline & 0.8 & -26.7 & 12.5 & $11.7 / 17.9$ \\
\hline & 0.9 & -38.5 & 16.5 & $15.2 / 24.0$ \\
\hline \multirow[t]{5}{*}{100} & 0.5 & 3.0 & 8.3 & $7.7 / 10.5$ \\
\hline & 0.6 & -6.9 & 7.9 & $7.2 / 9.7$ \\
\hline & 0.7 & -15.7 & 8.1 & $7.3 / 10.7$ \\
\hline & 0.8 & -24.5 & 9.2 & $8.1 / 14.3$ \\
\hline & 0.9 & -35.4 & 11.5 & $10.4 / 18.4$ \\
\hline \multirow[t]{5}{*}{200} & 0.5 & 3.9 & 6.9 & $6.2 / 6.7$ \\
\hline & 0.6 & -5.9 & 6.5 & $5.7 / 7.5$ \\
\hline & 0.7 & -14.6 & 6.6 & $5.8 / 8.9$ \\
\hline & 0.8 & -23.3 & 7.2 & $6.2 / 9.9$ \\
\hline & 0.9 & -33.8 & 8.7 & $7.4 / 13.6$ \\
\hline \multirow[t]{5}{*}{300} & 0.5 & 4.3 & 6.2 & $5.5 / 5.5$ \\
\hline & 0.6 & -5.6 & 5.8 & $5.1 / 5.4$ \\
\hline & 0.7 & -14.2 & 5.9 & $5.1 / 6.0$ \\
\hline & 0.8 & -22.9 & 6.4 & $5.3 / 7.0$ \\
\hline & 0.9 & -33.2 & 7.7 & $6.5 / 9.5$ \\
\hline \multirow[t]{5}{*}{600} & 0.5 & 4.8 & 5.1 & $4.3 / 4.4$ \\
\hline & 0.6 & -5.1 & 4.8 & $3.9 / 4.3$ \\
\hline & 0.7 & -13.7 & 4.8 & $3.9 / 4.9$ \\
\hline & 0.8 & -22.3 & 5.2 & $4.1 / 5.8$ \\
\hline & 0.9 & -32.5 & 6.3 & $5.0 / 8.1$ \\
\hline
\end{tabular}


No data editing applied

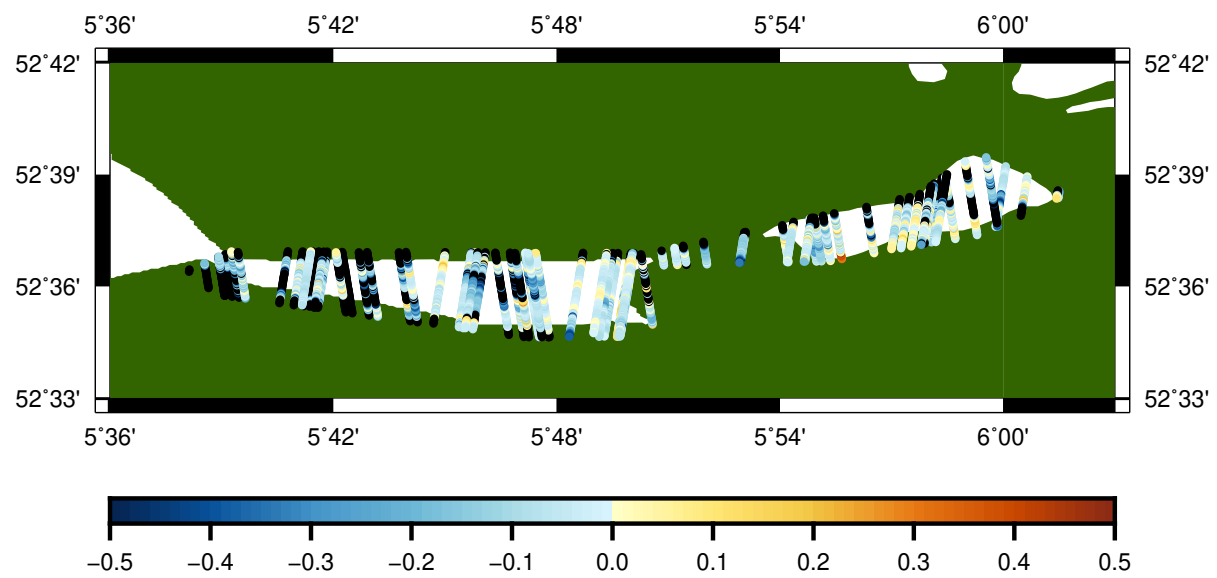

Data editing applied

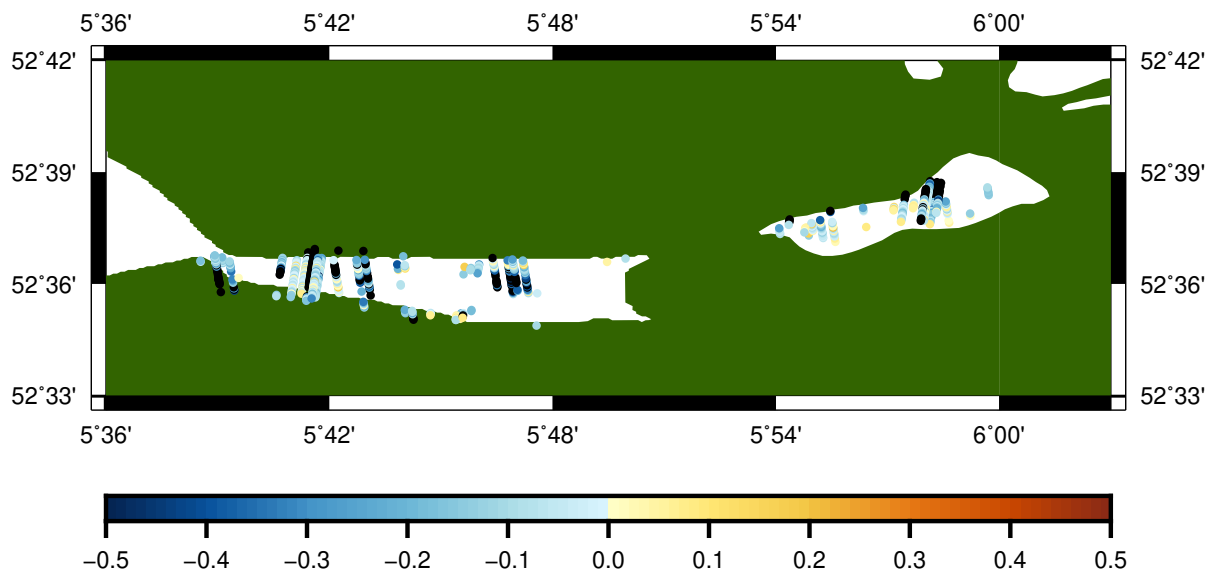

Figure 8: Differences [m] between interpolated gauge water-levels and CryoSat-2 estimates over Lake Ketelmeer and Lake Zwartemeer. Multilooking of 100 waveforms is applied and a threshold of 0.6 is used for retracking. 


\section{References}

\section{References}

[1] Berry, P. A. M., Garlick, J. D., Freeman, J. A., \& Mathers, E. L. (2005).

605

610

620

[7] Crétaux, J. F., Jelinski, W., Calmant, S., Kouraev, A., Vuglinski, V., BergéNguyen, M., Gennero, C., Nino, F., Abarca del Rio, R., Cazenave, A., \& Maisongrande, P. (2011). SOLS: A lake database to monitor in the Near Real

625

[8] Davis, C.H. (1997). A robust threshold retracking algorithm for measuring ice-sheet surface elevation change from satellite radar altimeters. 
IEEE Transactions on Geoscience and Remote Sensing, 35(4), 974-979, doi:10.1109/36.602540.

[9] Dinardo, S., Fenoglio-Marc, L., Buchhaupt, C., Becker, M., Scharroo, R., Fernandes, M. J., \& Benveniste, J. (2018). Coastal SAR and PLRM altimetry in german bight and west baltic sea. Advances in Space Research, 62(6), 13711404, doi:10.1016/j.asr.2017.12.018.

[10] Egido, A., \& Smith, W. H. (2017). Fully Focused SAR Altimetry: Theory and Applications. IEEE Transactions on Geoscience and Remote Sensing, 55(1), 392-406, doi:10.1109/TGRS.2016.2607122.

[11] Frappart, F., Calmant, S., Cauhopé, M., Seyler, F., \& Cazenave, A. (2006). Preliminary results of ENVISAT RA-2-derived water levels validation over the Amazon basin. Remote sensing of Environment, 100(2), 252-264, doi:10.1016/j.rse.2005.10.027.

[12] Göttl, F., Dettmering, D., Müller, F., \& Schwatke, C. (2016). Lake level estimation based on CryoSat-2 SAR altimetry and multi-looked waveform classification. Remote Sensing, 8(11), 885, doi:10.3390/rs8110885.

[13] Guccione, P., Scagliola, M., \& Giudici, D. (2018). 2D Frequency Domain Fully Focused SAR Processing for High PRF Radar Altimeters. Remote Sensing 2018, 10(12), 1943, doi:10.3390/rs10121943.

[14] Garcia-Mondéjar, A., Fornari, M., Bouffard, J., Féménias, P., \& Roca, M. (2018). CryoSat-2 range, datation and interferometer calibration with Svalbard transponder. Advances in Space Research, 62(6), 1589-1609, doi:10.1016/j.asr.2018.01.008.

[15] Jiang, L., Andersen, O. B., Nielsen, K., Zhang, G., \& Bauer-Gottwein, P. (2019). Influence of local geoid variation on water surface elevation estimates derived from multi-mission altimetry for Lake Namco. Remote sensing of environment, 221, 65-79, doi:10.1016/j.rse.2018.11.004. 
[16] Kleinherenbrink, M., Lindenbergh, R. C., \& Ditmar, P. G. (2015). Monitoring of lake level changes on the Tibetan Plateau and Tian Shan by retracking Cryosat SARIn waveforms. Journal of Hydrology, 521, 119-131, doi:10.1016/j.jhydrol.2014.11.063.

[17] Laxon, S. W., Giles, K. A., Ridout, A. L., Wingham, D. J., Willatt, R., Cullen, R., Kwok, R., Schweiger, A., Zhang, J., Haas, C., Hendricks, S., Krishfield, R., Kurtz, N., Farrell, S., \& Davidson, M. (2013). CryoSat2 estimates of Arctic sea ice thickness and volume. Geophysical Research Letters, 40(4), 732-737, doi:10.1002/grl.50193.

[18] Nielsen, K., Stenseng, L., Andersen, O. B., Villadsen, H., \& Knudsen, P. (2015). Validation of CryoSat-2 SAR mode based lake levels. Remote Sensing of Environment, 171, 162-170, doi:10.1016/j.rse.2015.10.023.

[19] Raney, R. K. (1998). The delay/Doppler radar altimeter. IEEE Transactions on Geoscience and Remote Sensing, 36(5), 1578-1588, doi:10.1109/36.718861.

[20] Roohi, S., Sneeuw, N., Benveniste, J., Dinardo, S., Issawy, E. A., \& Zhang, G. (2019). Evaluation of CryoSat-2 water level derived from different retracking scenarios over selected inland water bodies. Advances in Space Research, In Press, doi:10.1016/j.asr.2019.06.024.

[21] Schwatke, C., Dettmering, D., Bosch, W., \& Seitz, F. (2015). DAHITI - an innovative approach for estimating water level time series over inland waters using multi-mission satellite altimetry. Hydrology and Earth System Sciences, 19(10), 4345-4364, doi:10.5194/hess-19-4345-2015.

[22] Slobbe, C., Klees, R., Farahani, H. H., Huisman, L., Alberts, B., Voet, P., 680 \& De Doncker, F. (2019). The impact of noise in a GRACE/GOCE global gravity model on a local quasi-geoid. name Journal of Geophysical Research: Solid Earth, 124(3), 3219-3237, doi:10.1029/2018JB016470. 
[23] Smith, W.H.F. \& Egido, A.E. (2016). Fully focused coherent radar altimetry: precise datation, antenna motion, and transponder calibration, Living Planet Symposium, Prague, Czech Republic, 9-13 May, 2016.

[24] Smith, W.H.F. (2018). Spectral windows for satellite radar altimeters. Advances in Space Research, 62(6), 1576-1588, doi:10.1016/j.asr.2018.01.012.

[25] Song, C., Ye, Q., \& Cheng, X. (2015). Shifts in water-level variation of Namco in the central Tibetan Plateau from ICESat and CryoSat2 altimetry and station observations. Science bulletin, 60(14), 1287-1297, doi:10.1007/s11434-015-0826-8.

[26] Song, C., Ye, Q., Sheng, Y., \& Gong, T. (2015). Combined ICESat and CryoSat-2 altimetry for accessing water level dynamics of Tibetan lakes over 20032014. Water, 7(9), 4685-4700, doi:10.3390/w7094685.

695 [27] Villadsen, H., Andersen, O. B., Stenseng, L., Nielsen, K., \& Knudsen, P. (2015). CryoSat-2 altimetry for river level monitoring - Evaluation in the Ganges-Brahmaputra River basin. Remote Sensing of Environment, 168, 8089, doi:10.1016/j.rse.2015.05.025.

[28] Wingham, D. J., Francis, C. R., Baker, S., Bouzinac, C., Brockley, D., 700 Cullen, R., De Chateau-Thierry, P., Laxon, S. W., Mallow, U., Mavrocordatos, C., Phalippou, L., Ratier, G., Rey, L., Rostan, F., Viau, P., \& Wallis D. W. (2006). CryoSat: A mission to determine the fluctuations in Earths land and marine ice fields. Advances in Space Research, 37(4), 841871, doi:10.1016/j.asr.2005.07.027. 
${ }^{*}$ Declaration of Interest Statement

Declarations of interest: none. 
${ }^{*}$ Author Contributions Section

M. K., M. N. and C. S. conceived the idea. M. K., A. E. and W. S. developed the FF-SAR software. M. K. and C. S. developed the retracking software. M. K. performed the computations and data processing. M. K. and W. S. wrote the manuscript. All authors contributed to the discussion of the results. 